\title{
Preface: \\ From Science to Public Health: The Helicobacter pylori Case
}

\author{
Antoine Flahault MD PhD, ${ }^{1}$ \\ Theodore H Tulchinsky MD $\mathrm{MPH}^{2}$
}

\begin{abstract}
The Nobel Prize for Medicine was awarded in 2005 to JR Warren and BJ Marshall for their identification of the bacteria Helicobacter pylori as the cause of peptic ulcer diseases, establishing another link between infection and chronic diseases. This dramatic scientific breakthrough led to curative treatments which reduced suffering from many acute and chronic conditions previously managed with a wide array of medical and surgical care, mostly with poor results. This discovery also had major implications for public health and healthcare systems with reduction in hospitalisation and surgery as well as in gastric cancer. Potential future benefits for global health will be expanded through control of infection with this organism which affects half of the world population. Hopefully, a vaccine will soon be found to augment individual care and sanitary methods of control of this common bacterial infection. Professor Robin Warren here recalls the process of this monumental discovery.
\end{abstract}

Key words: Helicobacter pylori, chronic peptic ulcer diseases, history of medical science, Nobel Prize in Medicine 2005

\section{FROM SCIENCE TO PUBLIC HEALTH: THE HELICOBACTER CASE}

In 1982 two medical researchers in Perth, Western Australia discovered the bacteria Helicobacter pylori and identified its role as the cause of chronic peptic ulcer disease. For this, the Nobel Prize for Medicine in 2005 was jointly awarded to JR Warren and BJ Marshall. ${ }^{1}$ This is one of the great scientific breakthroughs in medicine in recent decades.

\footnotetext{
${ }^{1}$ Editor-in-Chief, Public Health Reviews; Dean, Ecole des Hautes Études en Santé Publique, Paris and Rennes, France.

${ }^{2}$ Deputy Editor, Public Health Reviews; Braun School of Public Health, Hadassah-Hebrew University, Jerusalem, Israel.
} 
Their discovery strengthened evidence of the potential of infectious organisms to cause chronic diseases. In this specific case, this led to a simple, inexpensive cure for one of the important groups of chronic diseases. H. pylori is associated with not only chronic peptic ulcers, perforations, and bleeding, but also with gastric cancer, the second leading cause of cancer deaths worldwide (803,000 in 2004) $)^{2,3}$

H. pylori is transmitted via the fecal-oral route from person to person, as well as in contaminated water and food, facilitated by crowding, poor sanitation and conditions of poverty. It is truly global in scope, present in some 50 percent of the world's population. ${ }^{4}$ Control of this disease by treatment of the infection, along with improved water safety and living conditions, has been associated with the decline in gastric cancer. ${ }^{3}$ Cure of chronic peptic ulcers has led to emptying of medical and surgical wards from chronic peptic ulcer diseases and their complications, including once common surgical procedures such as repair of perforated ulcers, vagotomy and gastrectomy. ${ }^{4}$

Robin Warren's Reminiscence on Helicobacter pylori reminds us of the excitement of new discoveries in medical sciences. In public health, we see this translated into an outstandingly successful capacity for clinical and public health management. Such advances bring great benefit to individual sufferers and to population health with significant reduction in costs as a result of reduced numbers of hospital days of care and surgical procedures no longer necessary. Someday, a vaccine will be available to control this continuing burden of disease and death due to $H$. pylori related diseases. ${ }^{5}$

This advance in clinical sciences has enhanced the effectiveness of clinical medicine. It has and will in the future strengthen the capacity of public health through wide scale application of many parallel efforts to improve medical care, sanitation, water safety, housing conditions, standards of living, and hopefully soon, immunization against this organism and its global effects.

We at PHR are grateful to Robin Warren for being part of our New Public Health issue of Public Health Reviews.

\section{REFERENCES}

1. Normark S. Presentation speech of the Nobel Prize for Physiology or Medicine, 2005. On behalf of the Nobel Foundation, Karolinska Institute, December 10, 2005. http://nobelprize.org/nobel_prizes/medicine/laureates/2005/presentationspeech.html (Accessed 22 January, 2010). 
2. Peek RM, Blaser MJ. Reviews: Helicobacter pylori and gastrointestinal cancer tract adenocarcinomas. Nature Rev. 2002;2:27-37.

3. National Cancer Institute. H. pylori and Cancer: Fact Sheet, October 17, 2006. (Accessed 22 January, 2010).

4. Brown LM. Helicobacter pylori: epidemiology and routes of transmission. Epidemiol Rev. 2000;22:283-97.

5. World Health Organization. Initiative for Vaccine Research: Helicobacter pylori http://www.who.int/vaccine_research/documents/Helicobacter_pylori/en/ index.html (Accessed 22 January, 2010). 